\title{
Islamistisk \\ maskulinitet og muslimske maskuliniteter
}

Af Shahin Gerami

Oversat af Mette Liv Mertz

Komplekse og ofte selvmodsigende konsdiskurser $i$ muslimske lande kan fore til en splitttelse for muslimske mand. Hvilken rolle spiller den globale hegemoniske maskulinitet samt nationale maskulinitetsfigurer $i$ konstruktionen af muslimsk og islamisk maskulinitet?

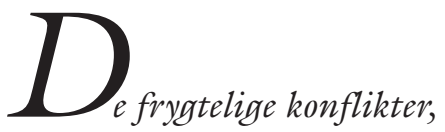

der grupperer folk under fejlagtige samlebetegnelser som 'Amerika', 'Vesten' eller 'Islam' og opfinder kollektive identiteter til et stort antal individer, som faktisk er temmelig forskellige, kan ikke forblive så kraftfulde, som de er, og de bor mode modstand. Vi har stadig de rationelle fortolkningsevner til ràdighed, som vi har faet $i$ arv fra vores humanistiske uddannelse; ikke som en sentimental frombed, der pålagger os at vende tilbage til traditionelle verdier eller de klassiske sprog, men som en aktiv praksis $i$ form af verdslig sekular rationel samtale.

Edward Said (2003, s. 23)

Det er blevet et udbredt mantra at anerkende islamiske ${ }^{2}$ kulturers, identiteters og fortolkningers utrolige mangfoldighed. Når dette er sagt, giver vi os derefter i kast med at identificere og analysere ligheder og endda fremsætte generaliseringer. I forlængelse af Edward Said og med lån fra Bayat vil jeg skelne mellem på den ene side islamistisk 
identitet som et abstrakt tankeværk, der pålægges af andre, og på den anden side muslimske identiteter som "konkrete, anfægtede og differentierede" identiteter, der skabes ved hjælp af individuelle eller gruppehandlinger. Bayat minder os om, at

“'islamisk samfund' bliver til en totaliserende 'forestilling', der ikke differentieres, mens 'muslimske samfund' aldrig som sådan er monolitiske, aldrig per definition er religiøse, samt at deres kulturer ej heller kan reduceres til religion alene" (Bayat 2003, 5).

Hvis vi accepterer denne dynamiske og selvbevidste kulturelle konstruktionsproces inden for muslimske samfund, bliver det mere plausibelt at forestille sig kønsidentiteter, der ikke udelukkende kan reduceres til islamisk femininitet; lige så lidt som maskuliniteter kan reduceres til én dimension af islamisk maskulinitet. I dette kapitel vil jeg undersøge den prototypiske, islamistiske maskulinitet samt muslimske maskuliniteter. Den første kategori anerkendes først og fremmest af andre; den anden er mere repræsentativ for maskulinitetskonstruktioner i muslimske lande.

Kønsdiskurser i muslimske kulturer fører en dobbelttilværelse. I lighed med andre kønsdikotomier har kønsidentiteter indfødte ansigter og stereotyper udadtil. De indfødte kvinders identiteter er mangefacetterede og bliver tiltagende synlige og forskelligartede. Mændenes diskurs er synlig som målestok og norm. Det er de vestlige kulturelle overleveringer af disse roller, der er meget synlige og stereotype.

Udforskningen af muslimsk maskulinitet har ikke fundet sin kulturelle kontekst i de islamiske samfund, men i situationen i den vestlige verden efter den 11. September. De vestlige folkekulturer har fået øje på deres dæmoner, og disse er muslimske mænd (Ratnesar \& Zabriskis 2004). De universelt genkendelige prototyper er skxggede pistolbærende mænd med partisantørklæde i lange gevandter eller militæruniformer til- hørende en eller anden islamistisk (læs: Terroristisk) organisation eller stat.

Analysen af maskuliniteter er en anden ny vestlig diskurs, der kan ende med at sprede sig til andre andre kulturer. Kimmel og Messner (2001) fastholder, at maskulinitetsstudier i USA er påvirket af feministisk teori, race- og klasseteori, queer teori og poststrukturalisme. Da maskulinitetsstudier som deres forgænger kvindestudierne er af vestlig oprindelse, bliver de konstrueret inden for vestlige kønsdikotomier. Hovedpræmisserne for disse studier antyder, at (a) køn er socialt konstrueret, hvorfor kønsidentiteter er tillærte; (b) magtulighed er samfundsskabt fremfor naturlig; (c) overlappene mellem race, klasse, køn og andre sociale sondringer privilegerer nogle kvindekategorier i forhold til andre; (d) maskuliniteters kønsprivilegier bør synliggøres og dermed udfordres; (e) den menneskelige biologi defineres af en kulturs sproglige redskaber, hvorfor biologiske race- og kønshierarkier er åbne for fortolkning, og endelig (f) heteroseksualitet er en given kulturelt privilegeret seksualitet. Maskulinitetsstudier har lånt fra alle de ovennævnte punkter og har flertydig konstruktion af maskulinitet som sit mål (Duroche 1990, Edwards 1990, Kegan Gardiner 2000, Pleck \& Sawyer 1974). Af ovennævnte præmisser er de første tre blevet indlemmet i mange muslimske landes akademiske og intellektuelle kønsdiskurser; for de øvrige særligt når det gælder seksualitet som socialt konstrueret - er der lang vej igen.

Der findes en spirende litteratur på den nordlige halvkugle, ${ }^{3}$ der analyserer muslimske mænds levede erfaringer med fokus på mellemøstlige/nordafrikanske lande (ME$\mathrm{NA}^{4}$ ). Nogle af artiklerne i Sinclair-Webbs (2000) bog udforsker for eksempel individuel handlekraft og gruppekonstruktion af maskuliniteter i denne region. En række artikler i et særnummer af tidsskriftet Men and Masculinities (2003) leverer supplerende perspektiver på maskulinitetsdiskurs i denne region. Ikke desto mindre er fokus 
forblevet på arabiske kulturer og mellemøstlige samt nordafrikanske samfund. Da de vestlige forestillinger om muslimske mænd ofte hentes fra stereotype opfattelser af mellemøstlige kulturer, vil jeg også fokusere på muslimske mellemøstlige og nordafrikanske samfund. Jeg kommer ikke til at dække den umådelige mangfoldighed i de central- og sydasiatiske lande samt i muslimske kulturer i europæiske og nordamerikanske samfund. Det følgende er et historisk ekstrakt af maskulinitetsmodaliteter i denne region siden koloniherredømmet.

I resten af teksten vil jeg udforske den globale hegemoniske maskulinitets rolle samt fremkomsten af nationale maskulinitetsfigurer, der er taget fra uafhængighedsbevægelserne og nationsopbygningprocessen i MENA-samfund. Siden vil jeg undersøge post-uafhængigheds- og koldkrigsperioden, der byder på forskelligartede repræsentationer af muslimske maskuliniteter på den nationale arena i regionen. I løbet af de seneste tre årtier er der opstået en islamistisk maskulinitet ud fra islamiske og fundamentalistiske bevægelser. Til slut vil jeg forsøge at synliggøre mangetydige muslimske maskuliniteter.

\section{GLOBAL HEGEMONISK MASKULINITET}

Findes der en universelt genkendelig hegemonisk maskulinitet? Denne vil i så fald uvægerligt være de medieeksponerede billeder af vestlig maskulinitet, der udbredes over hele kloden. Denne hegemoniske maskulinitet er uvægerligt hvid, kristen, heteroseksuel og dominerende. De virtuelle præsentationer af den foregår på biograflærredet og på internetsider. Dens legemliggjorte repræsentanter er vestlige politiske og militære ledere, der kigger ud fra avisernes forsider og fra fjernsynsskærmene. I denne CNNtidsalder er der selv i små landsbyer et par parabolantenner, der bringer disse billeder.

Den globale, hegemoniske maskulinitets opkomst går tilbage til den koloniale ekspansion. Tidligere invasioner eller voldtægt og plyndring af moderlandet var mere regionale og blev begået af grupper, der kulturelt og fysisk set i nogen grad lignede deres ofre. Ingen af dem var af samme størrelsesorden som et kolonialt herredømme udøvet af en anden race og en anden kultur. Den koloniale invasion intensiverede også sprogliggørelsen af voldtxgt af moderlandet begået af en indtrængende fremmed magt (Ahmed 1992). Som i mange andre kolonialiserede kulturer udgjorde det koloniale herredømme i de muslimske samfund en væsentlig udfordring af de lokale maskuliniteter i regionen. Mændenes ære var truet, og de følte sig kaldet til at beskytte den. På den måde blev kvindernes slør pludseligt symbol på mændenes xre på den nationale og politiske arena. En kvindes ære var ikke længere specifik for en klan, en stamme eller en mand; den blev symbol på den nationale ære. Kvindelige symbolikker er fremherskende inden for uafhængighedsbevægelser fra Egypten til det indiske delkontinent (Abdel Kader 1987, Gerami 1996).

Det, der bremser anerkendelsen af maskulinitetsstudier på den sydlige halvkugle, 5 er den sparsomme opmærksomhed, der rettes mod de kolonialiserede maskuliniteter i modsætning til den vestlige, hegemoniske maskulinitet. Feministisk teori har overvundet denne hindring ved både at anerkende vestlige feministiske tænkere og den righoldige litteratur, som feministerne på den sydlige halvkugle publicerer. I modsætning hertil bliver kolonialiserede maskuliniteter betragtet som de vestlige samfunds bindestregs-etniske maskuliniteter. Dette er i ikke så høj grad en mangel i vestlig kønsforskning, som det er et resultat af kønsdebattens kulturelle kontekst på den sydlige halvkugle. De islamiske samfund tager livtag med tværgående strømninger som globalisering, kulturel liberalisering, islamisk fundamentalisme og demokrati for blot at nævne nogle af dem. I denne kontekst vil en kønsdiskurs inden for en overskuelig fremtid komme til at dreje sig om kvinders rettigheder og roller. 
Hvor kvindestudier dukker frem og endda blomstrer mange steder på den sydlige halvkugle, forbliver maskulinitetsspørgsmål ikke integrerede. Selvfølgelig nødvendiggør den vestlige kønsdiskurs' privilegerede position betragtninger over kolonialiserede maskuliniteter. Dermed kan man håbe på, at der med tiden vil udspringe organiske maskulinitetsstudier af kønsstudierne på den sydlige halvkugle.

\section{NATIONAL KONSTRUKTION \\ AF MASKULINITET}

Den hegemoniske maskulinitets altgennemtrængende tilstedeværelse overskygger de nationale og kulturelle maskuliniteter i de fleste muslimske samfund. Selvfølgelig findes der synlige nationale maskulinitetsfigurer, og i visse tilfælde er de allestedsnærværende som i blandt andet i Egypten, Irak, Pakistan og Iran (Saghieh 2000). Selv om en national maskulinitet dominerer den sociale arena, forbliver den dog sekundær i forhold til den globale maskulinitet.

Under nationsopbygningen dukkede der stærke nationale ledere frem, som overskyggede de stammemæssige eller etniske maskulinitetsidealer. Heroiske modeller som Mustafa Kemal Atatyrk i Tyrkiet, Jamaal Abdul Nasser i Egypten, Irans Reza Shah og Pakistans Jinnah blev modstykkerne til den vestlige, hegemoniske maskulinitet. Med idealet om nationalitetsfølelse og en centraliseret stat fulgte idealet om en national leder, der indordnede regionale eller etniske maskuliniteter under sig. Efterhånden som disse ledere alle magtfuldt formede hver sin nationalstat, formede de også hver især en national maskulinitet ved at undertrykke andre konkurrerende, maskuline figurer. For eksempel forbød Reza Shah i Iran - som Atatyrk i Tyrkiet - ikke blot kvinders slør, han forhindrede også mænd i at bære etnisk, religiøs eller stammespecifik påklædning. Mænds offentlige udseende blev i begge lande indrettet efter vestlige koder i form af jakkesæt og slips.

\section{KOLDKRIGSMASKULINITETER}

Efterkrigs- og post-uafhængighedssituationen i de muslimske lande var domineret af den kolde krig mellem de to supermagter; derfor var alle statsoverhoveder underlagt en anden hegemonisk mandlig figur. For eksempel var den egyptiske Nasser under den sovjetiske Nikita Khrushchevs protektion, ligesom den iranske Shah og den pakistanske Butu nød skiftende amerikanske præsidenters beskyttelse fra Dwight D. Eisenhower til Richard Nixon. Jo txttere et land var på en dominerende kerne, des mere nærværende og dominerende var den hegemoniske maskulinitet i det pågxldende land. Eisenhower var nærværende mellem linjerne i iransk politik, men han var mindre synlig og måske mindre indflydelsesrig i den tyrkiske nationalitetsdiskurs, da Tyrkiet i mindre grad end Iran var politisk afhængig af USA.

Den postkoloniale periode bød på et hierarki af nationalstater, der gik hånd $\mathrm{i}$ hånd med et hierarki af maskulinitetsmodaliteter. En global, hegemonisk maskulinitet blev fulgt af nationale maskulinitetsfigurer, der opstod samtidig med de tilsvarende nationalstater. Uafhængighedsbevægelsernes nationale maskulinitet blev mere udbredt og mere gennemtrængende. Den kolde krig og afspændingsperioden blev et pusterum, hvor kulturelle diskurser kunne spredes, heriblandt kønsnarrativer, der bredte sig til de vestlige kulturers hovedstrøm. Heraf udsprang forskelligartede representationer af mangetydige maskuliniteter både i kernelandene og i de omkringliggende lande.

\section{KULTURELLE MASKULINITETER}

Efterhånden som forskellige variationer af vestlige maskuliniteter blev synlige - særligt når det gjaldt etnisk og racial mangfoldighed - gennemgik muslimske maskuliniteter visse omlægninger. Efter MENA-regionens uafhængighed oplevede de derboende muslimske mænd samme grad af ytringsfrihed, som blev de vestlige kulturers hegemoniske 
Tyrkiske filmplakater

mand til del. Ringen af maskuliniteter i de muslimske samfund blev sluttet, idet de begyndte som prækoloniale, spredte etniske, stammemæssige, landlige og bymæssige maskuliniteter og endte som uafhængighedsbevægelsernes nationale maskulinitet. Herefter videreudviklede de sig til forskelligartede maskuliniteter $\mathrm{i}$ perioden efter uafhængigheden og under den kolde krig.

Den fremherskende prototype forblev den stærke nationalistiske - i modsætning til den etniske - muslimske leder; massemedierne sørgede dog for alternative maskuliniteter. Disse afveg aldrig ret meget fra prototypen, men de var mindre barske og mere repræsentative for et givent samfunds klassemæssige og etniske mangfoldighed. Det var tilladt med svage mænd eller sjove figurer, og der blev gjort grin med $\mathrm{dem}$, når der skulle undervises i passende maskulinitet. De nationale medier, særligt de visuelle, eksperimenterede med forskellige variationer over etniske, arbejderklasse-, bondeog endda kriminelle maskuliniteter.

De nationale filmindustrier i lande som Egypten, Iran og Tyrkiet viste karakterskuespillere, der repræsenterede disse maskuliniteter. Disse var virile mænd, der var stærke både fysisk og moralsk set. De kunne være simple eller landlige som modsætning til de udspekulerede mænd fra byen. De forsvarede den gode kvindes ære og frelste af og til en kvinde fra vanære og fordærvelse (Ambrust 2000, Leaman 2001).
Hvad enten disse prototyper var en stærk leder, en helt fra arbejderklassen eller en historisk figur, var de typisk verdslige, men forpligtet til at efterleve islamisk moral. Den religiøse understrøm prægede alle personligheders og identiteters moralske dimensioner, kvindelige såvel som mandlige. Synderne og de onde maskuliniteter forlod den rette vej dikteret af islamiske moralske koder, mens de helte, der overholdt dem, reddede situationen.

Ud over det indfødte portræt af islamiske maskuliniteter udgjorde vestlige John Wayne-lignende eksempler på maskulinitet magtfulde modeller. Jeg husker, at mange af rollerne i amerikansk fjernsyns bedste sendetid - såsom Dr. Kildare, westerncowboys og endda Perry Mason - blev kopieret og efterlignet i iranske tv-produktioner og radioudsendelser. Det samme skete i den egyptiske og tyrkiske tv-produktion.

\section{DE IRANSKE BIDRAG I FORM AF KRIGEREN OG SHAHID'EN6}

Da de iranske helte var shiitter, havde de samme maskuline egenskaber som Ali og Hussein; henholdsvis profetens svigersøn og barnebarn. Shiitter tror, at Profeten før sin død udpegede sin svigersøn Ali og dennes efterkommere til at være hans rette arvtagere. Men efter Profetens død valgte samfundets ældre hans svigerfar Abu Baker som den første kalif. Ali blev til sidst den fjerde kalif og regerede i fem år, før han 
blev snigmyrdet af en militant gruppe. I 680 e.Kr. forsøgte hans anden søn Hussein at generobre magten fra kalif Yazid for at genoprette det sande islamiske samfund. Han blev besejret i slaget ved Karbala, og han og mange i hans følge blev dræbt.

Disse to idealer for retfærd har farvet forestillingen om retfærdighed og moral samt kønsidealer for maskulinitet i shiitiske samfund. Ali og Hussein afspejler forskellige typer maskulinitet i den shiitiske maskulinitetskonstruktionspakke. Alis mandige "Kriger"persona er blevet reproduceret i shiitiske kulturer fra Pakistan til Libanon, fra lyrik til biograflærred. Hussein repræsenterer en anden type maskulinitet, nemlig "shahid'en", det vil sige en martyr. Husseins model blev i den iranske bevidsthed indbegrebet af uretfærdighed og nægtede rettigheder (Hegland 1995). Regionens shiitiske samfund lovpriser og begreder ham hvert år i gadeteater (tazieh). Hvor den iranske filmindustri bemægtigede sig myten om Ali og præsenterede nye folkehelte, blev Husseins persona som shahid indbegrebet af gadeteatret og blev senere integreret i konstruktionen af islamistisk maskulinitet.

\section{ISLAMISTISK MASKULINITET}

I det følgende skelner jeg mellem islamistisk maskulinitet og mangetydige muslimske maskuliniteter. Førstnævnte er et produkt af fundamentalistiske modstandsbevægelser og vestliger medier. Nummer to er virkelige mænds kønsidentiteter, som de formes på tværs af nationalitets-, etnicitetsog klasseskel.

I løbet af 1970'erne begyndte mellemøstlige eksperimenter med vestlige former for udvikling såsom kapitalisme, socialisme eller endda blandingsøkonomi at udvise tegn på at krakelere. Den islamiske revolution i Iran markerede den første reaktion på disse eksperimenters sammenbrud og - set i bakspejlet - den efterfølgende koldkrigspolitik. Den iranske revolution markerer begyndelsen på islamisk fundamentalisme som en løsning på de muslimske nationers problemer og som et politisk statsgrundlag. I slutningen af det 20. århundrede bredte fundamentalistiske bevægelser sig over hele regionen og bidrog til, at ét bestemt maskulinitetsbillede blev fremtrædende. Det blev et svar på den hegemoniske, globale maskulinitet samt dennes forskellige nationale udgaver. Fundamentalistiske bevægelser deler i mange muslimske lande elementer af en tilbageskuende ideologi, der skal genindsætte det tidligere 'rene' islamiske samfund. Derfor dikterer kønsideologierne religiøst forordnede pladser for hvert køn. Der findes megen litteratur, der dokumenterer islamiske fundamentalismers doktrinære befalinger og regler for kvinder (Afshar 1998, Gerami \& Safiri, under udgivelse, Mir-Hosseini 1999, Shehadeh 2003). Mænds idealer inden for disse ideologier nyder nogen opmærksomhed (Gerami 2003a). Kurzman (2002) giver et kortfattet sammendrag af karakteristika ved islamisk fundamentalisme og en række berømte islamiske mænds socioøkonomiske baggrund. Peteet (2000) bidrager til vores forståelse af konstruktionen af islamisk maskulinitet i de besatte områder. Den voksende mængde tekstmateriale om islamiske forskrifter, jihad og Koranens lære fremmer udvekslingerne om muslimsk identitet og muslimske mænd (Esposito 2003, Lawrence 1998, Soroush 2000).

Den islamistiske maskulinitet er et produkt af denne periode. Der er to hovedfortællinger, der præger den prototypiske islamistiske maskulinitetsdiskurs i hele verden; jibad og shabadat. Flertallet af muslimer skelner uanset deres orientiering mellem "den store jihad, det vil sige den personlige og åndelige indre strid, og den lille jihad, der har med krigsførelse at gøre" (Esposito 2003, 38). Det er krigsvarianten, der kendes af ikke-muslimer, og som former fortællingen om denne islamistiske maskulinitet.

Shahadat-fortællingen (om martyrium) befinder sig ligeledes på både et personligt og et offentligt plan (Gerami 2003b, 266). 
Når muslimer sværger, at "der ikke findes andre guder end Allah, og at Muhammed er Allahs profet", sværger de, at de vil kæmpe mod kødets lyster, polyteisme og stræben efter jordisk gods. Det offentlige aspekt af shahadat består i at ofre sit liv i en jihad for at beskytte Islam eller en islamisk nation. Disse personlige planer er selvsagt blevet indordnet under fortællingernes offentlige elementer, og resultatet er den moderne islamistiske maskulinitet.

De irakiske styrkers invasion af Iran i 1980 dannede det perfekte grundlag for ovennævnte fortællingers konvergens. Den islamiske revolutionsideologi og Ayatollah Khomeinis karismatiske kraft havde allerede skabt en frugtbar grobund for overførslen af de personlige aspekter ved jihad og shahadat til en social bevægelses offentlige arena. Disse fortællinger udviklede sig yderligere med den irakiske invasion og den efterfølgende 8-årskrig som bagtæppe. Sådan fødtes den moderne myte om shahid'en. Selv om shahadat-idealet blev brugt af de afghanske mujahideen'er mod Sovjetunionen - og af den palæstinensiske besættelsesmodstand - havde ingen af dem samme gennemslagskraft og fremtrædende position som krigen mellem Iran og Irak.

Den iranske modstand institutionaliserede og internationaliserede shabadat og dens maskulinitetsprototyper. Shahid'en er den islamistiske maskulinitets udtrykte billede. Han er ung, ren og uskyldig (jomfruelig) og kæmper mod de vantro, mens han bevidner sin tro.

Der findes forskellige kulturelle varianter af denne maskulinitetsgenerator, men ingen væsentlig afvigelse fra dens mandlige, rene og gudsfrygtige essens. De levende eksemplarer på islamistisk maskulinitet rummer måske ingen af ovennævnte kendetegn, men de gør krav på rangen shohada (flertalsformen af shahid) i kraft af deres offer. I krigen mellem Iran og Irak ansporede denne heltedyrkelse mange drenge til at blive bosiji (frivillige). I resten af verdens øjne var de børnesoldater eller kanonføde, men i den islamistiske diskurs var de martyrer. Dette martyrideal opslugte senere regionen. I Egypten blev forskellige opstande tilskrevet Det Muslimske Broderskab ( $\mathrm{Al}$ ikvans al-muslimun). Deres helte tæller blandt andet præsident Anwar Sadats morder. Alle flykaprerne 11. september 2001 legemliggør denne prototypes karakteristi$\mathrm{ka}$, og for mange i regionen lever de op til shahid-personaen.

Fortidens krigerriter og de moderne hæres soldaterritualer markerer overgangen fra barn- til manddom. I kulturer med en belejringskomponent signalerer militære maskulinitetsaspekter ankomsten og inklusionen af 'manden' som agtet og xret borger (Arkin \& Dobrofsky 1978, SinclairWebb 2000). Kaplan (2000) og Peteet (2000) illustrerer, hvordan maskuliniteter smedes gennem daglige voldelige konfrontationer mellem israelske soldater og stenkastende palæstinensiske unge. Soldaterne og de unge opnår deres agtede og xrede manddom via offerhandlinger i troens, landområdets og ærens navn.

Kaplan fastholder, at militærtjeneste i Israel tildeler soldaterne "anerkendte og legitime temaer, der er nært forbundet med hegemonisk maskulinitet" inden for den zionistiske forestillingsverden $(2000,136)$. Denne maskulinitet er herefter kørt i stilling og parat til at kæmpe mod fjendens maskulinitet. Da den ritualiserede kamp tildeler de unge israelske mænd hegemonisk maskulinitet, gør de palæstinensiske drenge sig derfor fortjent til en militant manddom ved at blive tæsket og indespærret af soldaterne (Peteet 2000). Ifølge Sahmmas (citeret hos Peteet 2000, 106) anvender det israelske militær ikke det hebraiske ord for "børn”, når der henvises til de palæstinensiske drenge. I stedet hedder det sig, at en ung mand på 10 blev dræbt af soldater. Den militære indvielse, som forvandler unge israelere til hegemoniske mænd, når de slår, forvandler unge palæstinensere til frihedskæmpere og måske martyrer. Når den palæstinensiske unge løslades fra fængslet, 
nyder han herefter agtelse og respekt i lokalsamfundet.

Islamistisk maskulinitet er en af kombattanterne i denne globale guerillakrig om hegemonisk maskulinitet. Shahid er som kategori abstrakt og kan ikke at rumme de impliceredes mangfoldighed, herunder kvinder ("Hamas woman bomber kills Israelis", 2004). Kimmel pointerer, at køn, "deres maskulinitet, deres følelse af maskulin fortrinsret og deres kuldsejlede ambitioner" $(2004,82)$ er den fællesnævner, der forbinder Timothy McVeigh, Adolf Hitler og Mohammad Atta. Kimmel og flere andre har endvidere peget på at eksponenterne for dette maskulinitetsmærkes er den fælles middel- og lavere middelklassebaggrund (Gerami 2003b, Wickham 2002, Wiktorowicz 2001).

\section{MUSLIMSKE MASKULINITETER}

Flertallet af mændene i MENA-landene er unge mænd i byerne. De er under 30 år gamle og født af middel- eller arbejderklasseforældre i byen. Hovedparten af denne befolkningsgruppe har en gymnasieuddannelse, og nogle af dem har et par års videregående uddannelse. Ikke desto mindre er de dårligt rustede til de få eftertragtede job inden for det tekniske felt. Deres familiers forventninger dikterer, at manuelt arbejde er uattraktivt, hvilket begrænser deres beskæftigelsesmuligheder. Denne store gruppe befinder sig i centrum for to store modstrømninger: Islamisk fundamentalisme og kulturel liberalisering. Idealet om en velstående kernefamilie er uden for de fleste medlemmer af denne gruppes rækkevidde. Islamisk fundamentalisme er svaret for en del af denne befolkningsgruppe. Fundamentalismens strenge påbud om en asketisk livsstil udøver dog - i modsætning til de vestlige mediers synspunkter - ikke en stor tiltrækningskraft.

De xldre generationer af middelklassemænd i byerne har deres egne genstridige problemer at slås med. Disse grupper, som er flyttet til byerne eller er født der, besidder i nogen grad videregående uddannelse. De fleste er små købmænd eller embedsmænd. Da de skal tjene til familiens ophold, er de stillet over for svimlende omkostninger forbundet med bolig og store familier, der for det meste består af mere end fire. Inflation, passive regeringer, korruption og slægtskabsforpligtelserne skaber tilsammen modsatrettet pres (Salehi Esfahani \& Taheripour 2002). Denne gruppe kan godt være tilbøjelig til at byde den islamiske fundamentalismes restriktioner på kvinders færden velkommen, da de så bedre kan kontrollere deres kvinder i byerne. Derpå betaler de for de hjemmegående hustruer og døtre, som ikke kan bidrage til familieindkomsten. Desuden skal de håndtere deres pubertetsbørns krav om nye forbrugsgoder.

Mænd med lav indkomst $\mathrm{i}$ byerne og på landet er endnu mere frustrerede over ovennævnte stressfaktorer. Da de er skuffede over den manglende udsigt til beskæftigelse på landet og i de små byer, flytter de som de første til de større byer i regionen. Her slutter de sig til mængden af de underog ubeskxftigede og bidrager til forøget kriminalitet. Efterspørgslen på manuelt arbejde i byerne begrænser sig til byggepladser og enkelte servicefag. Disse job - når de da er ledige - kaster ikke megen opsparing, der kan sendes til den efterladte familie eller bruges på bryllupsudgifter, af sig. Islamistiske organisationer er svaret for nogle af disse unge mænd, men de kan ikke tilbyde dem arbejde eller betale udgifterne for det store antal rekrutteredes.

Mændene fra den øvre middelklasse, som er beskæftiget inden for akademiske eller liberale erhverv, drager fordel af et liv med forbrugerisme og meningsfuldt arbejde. De er økonomisk set bedre stillede og kan finansiere deres børns drømme. På trods af deres bidrag til systemet forbliver de teknokrater i de fleste styrer og erfarer, at deres vej mod politisk deltagelse er spærret. De skal hele tiden bekymre sig om deres børns 
fremtid. De fleste universiteter kan ikke honorere kravene fra en stor gruppe unge ansøgere, hvorfor mænd tilhørende denne klasse samt deres familier leder andetsteds efter en bedre fremtid for deres børn. For manges vedkommende starter denne bedre fremtid i visumkøerne ved vestlige konsulater (Gerami 2003a).

Interessant nok er der som i USA flere kvinder end mænd på de videregående uddannelser i mange muslimske lande. I lande som Egypten, Iran og Tyrkiet er der flere kvindelige end mandlige studerende, der består de omfangsrige optagelsesprøver og starter på universitetet (Sachs 2000, UNESCO 2000-2001). Der er adskillige faktorer, der har bidraget til denne omvendte kønssituation, heriblandt det stigende antal mødre i byerne, som har en studentereksamen og bifalder, at deres døtre tager en videregående uddannelse. Det er mere accepteret for unge mænd at rejse til udlandet for at uddanne sig end for enlige kvinder, og derfor er flere stipendier til studier i udlandet øremærket til mænd. Faktisk kræver visse lande som for eksempel Saudi-Arabien, at unge kvinder, der rejser i udlandet, ledsages af en voksen. De høje leveomkostninger har ført til en udskydelse af ægteskab for begge køn, og de unge familier har brug for kvindernes indkomst for at opnå eller opretholde deres middelklasselevestandard.

For mænds vedkommende har videregående uddannelse ikke indfriet løftet om det 'globale gode liv'. Bedreuddannede kvinder får nogle mænd til at føle sig usikre og udfordrer deres følelse af maskulin fortrinsret. Desuden har ansvaret forbundet med at være den mandlige forsørger muligvis bidraget til de unge mænds foragt for en videregående uddannelse, der ikke garanterer dem et udbytte. Således søger visse unge mænd efter nye måder (Merton 1968) at opnå det gode liv for dem selv og deres familier på.

Muslimske maskuliniteter produceres inden for disse strukturelle og kulturelle strømninger (Lubeck 2000). Islamiske fun- damentalismer med deres tilknyttede vagtsomhed over for vestligt hegemoni, opblødningen af traditionelle kønsroller samt et stærkt ønske om kulturel autenticitet fordrer en konservativ tilgang. Den økonomiske globalisering har reduceret mikrolandbrugsproduktionen og efterspørgslen på landarbejde, men den har ikke formået at skabe fabriksjob, man kan leve af i byerne (Coes 1995, Onis \& Webb 1994). Passive myndigheder, der styres af en enkelt familie eller socialt lag, er ikke fleksible nok til at imødegå disse kræfter. Herudover har palæstinensernes lidelser for de fleste muslimers vedkommende medført en kronisk skyld- og skamfølelse uanset etnisk identitet (kurdisk, arabisk eller iransk) eller religiøs overbevisning (armenere, druser eller andre). Den mellemøstlige/islamiske psyke pines af palæstinensernes ydmygelser og smerte, hvilket af og til fører til desperate handlinger.

Der er andre strømninger, som fortjener opmærksomhed, for eksempel informationsstrømmen via internettet, international migration og den øgede bevidsthed om Vesten som det forjættede land samt kvindebevægelser af skiftende intensitet. Desuden er den muslimske befolkning på verdensplan meget ung; medianalderen i MENA-regionen ligger omkring 21 år (FN's befolkningsorganisation (UNPD) 2002). Demografien i sig selv varsler en omorganisering af kønsroller i det næste årtusind. Mere end nogensinde vil denne store befolkningsgruppe forme deres maskuline identitet under påvirkning af et hegemonisk, globalt systems økonomiske og kulturelle kræfter. Deres reaktioner afhænger af deres socioøkonomiske baggrund og deres opfattelse af forhåndenværende muligheder.

I de sydafrikanske ghettoer i Cape Town kombinerer de unge for eksempel machismo og selvtægt i kampen mod pushere og generobrer deres kvarter i Islams navn (Bangstad 2002, 10). I Frankrig går 'genkonverterede' andengenerationsindvandrerunge i gaderne og forkynder Islam. "De er mellem 
18 og 36 år gamle og bor fortrinsvis i de franske forstæder, hvor de ophobede problemer med arbejdsløshed, eksklusion og racisme er fremherskende" (Khedimellah 2002, 20).

\section{LIBERALE MASKULINITETER}

Muslimske maskuliniteter reagerer også på de positive aspekter ved globaliseringen, nemlig kulturel tolerance og politisk liberalisering. I skrivende stund udfordrer liberaliseringen det iranske eksperiment med at tilpasse demokrati til Islam. De iranske vælgere forbereder sig på det parlamentariske Majles-valg i februar 2004. Vogternes Råd, som er en konstitutionel forsamling, der primært består af konservative gejstlige, er ansvarligt for at kontrollere, at alle lovforslag og love er forenelige med de islamiske befalinger. Rådet skal også undersøge kandidater til parlamentet eller præsidentposten ved at granske deres generalieblad med henblik på en vurdering af deres islamiske værdighed. I forbindelse med det aktuelle valg har Rådet afvist omtrent 3.000 kandidater, heriblandt de fleste nuværende representanter.

Den Islamiske Republik er en eksperimenterende model, der medierer mellem Islam og moderniteten. Individets borgerrettigheder, sekularisme, organisationsmæssig adskillelse af tro og statsapparat, en universel medborgerskabsdefinition hinsides køn og etniske og religiøse restriktioner er alt sammen noget, der bliver debatteret.

Børnene af revolutionen, der blev født i slutningen af krigen, kalder sig selv "generation 3" og fører an i denne debat. Deres middelklasseforældre i byerne troede på små familier og overøste deres afkom med det, de gerne selv ville have haft, særligt med hensyn til uddannelse. Nu er denne generation blevet voksne, og de er utålmodige, unge og teknisk velfunderede med globale forventninger. De står over for en anden gruppe børn af revolutionen fra deres egen generation, mestendels fra de lave- re samfundslag i byerne; disse hælder til islamiske organisationer og er loyale over for regimet og revolutionen.

Familierne er også på børnenes side. Familier til shahid'er eller krigsveteraner er påpasselige med at holde den revolutionære og islamiske ånd $\mathrm{i}$ live og præsent. Disse familier har meget at miste, både psykologisk og økonomisk. Smerten forbundet med at ofre en søn for en sag er mindre ubærlig, når der hæges om hans eftermæle, end hvis han bliver glemt, eller minderne om ham aftager. Disse familier modtager håndgribelig støtte fra den enorme Shahid Foundation $\mathrm{i}$ form af pension, materielle goder og favorable vilkår ved ansættelse eller optagelse på universitetet.

Universitetsstuderende er modtendensen til shahid'erne. Disse glatbarberede unge byboer går ind for liberaliseret uddannelse, fri adgang til borgerrettigheder og privatisering af religiøse institutioner og praksisser. De ønsker at omgås frit med det modsatte køn, og de synes, at påbud om en bestemt påklædning og opførsel er ydmygende og undertrykkende. De organiserer sig ofte i studenterprotester, sit-ins og mediebegivenheder for at gøre deres holdninger til diverse spørgsmål gældende. I modsætning til islamisterne, der hovedsageligt skyder skylden på udenforstående, imperialisterne eller globaliseringen, bebrejder denne gruppe de nationale ledere.

De iranske liberale maskuliniteter svarer til en begyndende ungdomsbevægelse i de muslimske samfund. Denne bevægelse er anti-islamistisk og anti-shahid. Den er et produkt af - og et bidrag til - en ny modernitetsdiskurs, der transcenderer den gamle dikotomi mellem 'Vesten og Resten'. Den er ikke et forsøg på at modernisere Islam, men snarere på at designe en islamiseret modernitet, der er forenelig med pluralisme og reformation (ijtihad), og som kan afvikle religiøs retslære. De liberale muslimske mænd, som er banebrydende for denne fortælling, er forfattere som Soroush, Mujtahid-Shabastari og Kadviar samt den algeri- 
ske oppositionsleder Abbasi Madani. Denne nye art og deres ideologiske ledere er imod "religiøs ideologisering, hvilket vil sige forvandlingen af religion til et instrument for fanatisme og had" (Soroush 2000, 21). Den anden generation af unge født i Vesten eller muslimske konvertitter i Europa (Allievi 2002) er et ekko af samme indstilling. Progressive muslimske mænd af denne type låner fra kvinde- og miljøbevægelserne, når de skal genfortolke Koranen, og de påtager sig nye muslimske identitetskonstruktioner (Esack 2003). De er modstandere af ekskluderende ideologier som fundamentalisme og wahabittisme og stræber efter en diskurs om tolerance og kønsmæssig omdefinering. Dette er en hårfin balancegang, særligt for muslimske mænd i den vestlige verden. Mens de kæmper for at blive accepteret, bliver de udskilt af offentligheden og profileret af myndighederne. I de konservative muslimers øjne mangler de etnisk autenticitet og har givet deres sande tro i pant for adgang til Vesten. De dominerende grupper i deres vestlige hjemlande ser dem derimod som mistænkelige, som det er klogt at holde et vågent øje med.

\section{EFTERSKRIFT}

Mine personlige erfaringer tyder på, at mænds klasseposition skaber flere fællesnævnere end deres etniske og religiøse baggrund tilsammen. De to første år, jeg gik på universitetet, lejede jeg en lejlighed af en armensk kvinde i en lavere middelklassebydel i det gamle Teheran. Min udlejer, som var forretningskvinde, tildækkede som sine muslimske naboer sit hår, men på en lidt anden måde. De fleste butikker og forretninger tilhørte etniske iranere. Det mest kendetegnende ved lokalsamfundet var ikke dets religiøse flertydighed, men snarere dets udprægede sproglige mangfoldighed. Mændene så ud, opførte sig og drev deres forretning og familie på stort set samme måde. Den eneste vej til at spore deres religiøse baggrund på gik gennem sproget. De talte farsi med hinanden, men med deres etniske gruppe slog de over i armensk, tyrkisk og kurdisk, somme tider med et stænk af assyrisk. Som det forventedes, kendte de deres kunders baggrund og tiltalte dem på det sprog, der passede til. Klasseforskellen adskilte mændene i mit kvarter dels fra den lavere middelklasse i den gamle bydel og dels fra forstædernes middelklasse og senere beboerne i yuppieejerlejlighederne. Hvorvidt de var sunni- eller shiia-muslimer, kristne armenere, kalimiske jøder eller de senere marxistiske leninister var mindre vigtigt.

Mænds sociale klasse og deres dertilhørende livsmuligheder er de primære faktorer i deres identitetskonstruktion. Deres etnicitet, landlige eller bymæssige baggrund og religiøse overbevisning bidrager til deres handlekraft i forbindelse med konstruktionen af maskulinitet ud fra modsatrettede tendenser og pres. Feministiske mænd modsætter sig udbredelsen af sharia, for den kan begrænse kvinders borgerrettigheder. I modsætning til forventningen om, at islamiske stater vil øge mænds fordele, klarer mænd i lande med sharia-lovgivning sig ikke bedre økonomisk set, og deres livsmuligheder med hensyn til helbred, uddannelse eller højnet levestandard er heller ikke forbedrede. Hvis fundamentalistiske regeringer forbedrede mænds muligheder, ville afghanske mænd være foregangsmænd for de muslimske maskuliniteter.

Schacht og Ewing (1998) minder os om en feministisk dagsorden, der handler om at "skabe ikke-undertrykkende realiteter" ved at udfordre "de usynlige måder, hvorpå patriarkalske og tilsvarende kønsantagelser har domineret vores begreber" (s. 14). Den aktuelle dæmonisering af brune mænd i de vestlige, navnlig amerikanske, medier skader os alle. De amerikanske mediers allestedsnærværelse og gennemtrængende kraft ansporer os til at udfordre deres fortsatte bagvaskelse af muslimske og mellemøstlige mænd. Det er nødvendigt at studere muslimske maskuliniteter, for sådanne studier vil understøtte kvinde- og kønsstudier i de 
muslimske samfund, de vil gøre det lettere for muslimske mænd at forstå og forhandle hastige sociale forandringer, og de vil bistå vestlige maskulinitetsstudier $\mathrm{i}$ at række ud over deres (selv)optagethed af seksualitet. Dette vil åbne mulighed for en videre indarbejdelse af imperialismediskursen i den almindelige kønsdiskurs og måske endda i populærkulturen. Endelig vil det bidrage til en øget synliggørelse af virkelige muslimske maskuliniteter.

\section{Noter}

Tak til forfatteren for tilladelse til at bringe oversættelsen af denne artikel. Oversat fra "Islamist Masculinity and Muslim Masculinities" i: Kimmel, M.S., Hearn, J., Connel, R.W. (eds.) (2005): Handbook of studies on Men and Masculinities, Sage, Thousand Oaks, London, New Delhi.

1. I det følgende skelnes mellem det engelske "Islamist" (islamistisk) og "Islamic" (islamisk). O.a. 2. Se note 1. O.a.

3. "The North". Kan af gode grunde ikke oversættes med "Norden". O.a.

4. Forkortelsen står for "Middle Eastern/North African". O.a.

5. "The South". "Syden" ville lyde enten som et ferieparadis eller som sydstaterne i USA. O.a. 6. Arabisk term for hellig kriger. O.a.

\section{LITTERATUR}

- Abdel, Kader S. (1987): Egyptian women in a changing society, 1899-1987. Lynne Rienner, Boulder, Colorado.

- Afshar, H. (1998): Islam and feminism: An Iranian case study. St. Martin's, New York.

- Ahmed, L. (1992): Women and gender in Islam: Historical roots of the modern debate. Yale University Press, New Haven, Connecticut.

- Allievi, S. (december 2002): "Converts and the making of European Islam”. International Institute for the Study of Islam in the Modern World Newsletter, 11. Hentet 10. februar 2004 fra www.isim.nl/files/newsl_11.pdf.

· Arkin, W., \& Dobrofsky, L. R. (1978): "Military socialization and masculinity". In: Journal of Social Issues, 34(1), 151-168.

Armbrust, W. (2000): "Farid Shauqi: Tough guy, family man, and cinema star". In: M. Ghoussoub
\& E. Sinclai-Webb (red.), Imagined masculinities: Male identity and culture in the modern Middle East. Saqi, London.

- Bangstad, S. (december 2002): "Revisiting PAGAD: Machoism or Islamism?” International Institute for the Study of Islam in the Modern World Newsletter, 11, 10.

- Bayat, A. (december 2003): "The use and abuse of "Muslim Societies"”. International Institute for the Study of Islam in the Modern World Newsletter, 13. Hentet 10. februar 2004 fra www.isim.nl/files/newsl_13.pdf.

. Coes, D. V. (1995): Macroeconomic crises, policies, and growth in Brazil, 1964-1990. World Bank, Washington DC.

- Durouche, L. (1990): "Male perception as social construction". In: J. Hearn \& D. Morgan (red.), Men, masculinities and social theory. Unwin $\mathrm{Hy}-$ man, London.

. Edwards, T. (1990): "Beyond sex and gender: Masculinity, homosexuality and social theory". In: J. Hearn \& D. Morgan (red.), Men, masculinities and social theory. Unwin Hyman, London.

- Esack, F. (2003): "In search of progressive Islam beyond 9/11". In: O. Safi (red.), Progressive Muslims. Oneworld, Oxford, UK.

- Esposito, J. (2003): Unholy war. Oxford University Press, New York.

- Gerami, S. (1996): Women and fundamentalism: Islam and Christianity. Garland, New York. - Gerami, S. (2003a): "Men and immigration". In: M. Kimmel \& A. Aronson (red.), Men and masculinities: A social, cultural, and historical encyclopedia. ABC-CLIO, Santa Barbara, Californien. - Gerami, S. (2003b): "Mullahs, martyrs and men: Conceptualizing masculinity in the Islamic Republic of Iran. Men and masculinities, 5(3), 257-295.

- Gerami, S., \& Safiri, M. (under udgivelse): "Qur'an: Women and modern interpretations, late 1800 to the present". In: S. Joseph \& A. Najmabadi (red.), Encyclopedia of women and Islamic cultures. Sage, Thousand Oaks, Californien.

. "Hamas woman bomber kills Israelis" (14. januar 2004): BBC News World Edition. Hentet fra http://news.bbc.co.uk.

. Hegland, M. (1955): “Shi'a women of Northwest Pakistan and agency through practice: Ritual, resistance, resilience". Political and Legal Anthropology Review, 18. 65-79.

- Kaplan, D. (2000): “The military as a second bar mitzvah: Combat service as initiation to Zionist masculinity". In: M. Ghoussoub \& E. Sinclai-Webb (red.), Imagined masculinities: Male identity and culture in the modern Middle East. Saqi, London. · Kegan Gardiner, J. (2000): “Introduction”. In: J. 
Kegan Gardiner (red.), Masculinity studies and feminist theory. Columbia University Press, New York. . Khedimellah, M. (december 2002): "Aesthetics and poetics of apostolic Islam in France". International Institute for the Study of Islam in the Modern World Newsletter, 11, 20.

. Kimmel, M. (2004): “Gender, class and terrorism”. In: M. Kimmel \& M. Messner, Men's lives (6. udgave). Allyn and Bacon, Boston.

· Kurzman, C. (2002, efterår/vinter): "Bin Laden and other thoroughly modern Muslims". Contexts, 13-20.

- Lawrence, B. (1998): Shattering the myth: Islam beyond violence.: Princeton University Press, Princeton, New Jersey.

- Leaman, O. (2001): Companion encyclopedia of Middle Eastern and North African film. Routledge, London.

. Lubeck, P. (2000): "The Islamic revival: Antinomies of Islamic movements under globalization". In: R. Cohen \& S. M. Rai (red.), Global social movements. Athlone, New Brunswick, New Jersey.

- Merton, R. (1968): Social theory and social structure. Free Press, New York.

Mir-Hosseini, Z. (1999): Islam and gender: The religious debate in contemporary Iran. Princeton

University Press, Princeton, New Jersey.

. Onis, Z., \& Webb, S. B. (1994): "Turkey: Democratization and adjustment from above". In: S.

Haggard \& S. B. Webb (red.), Voting for reform.

Oxford University Press, Oxford, UK.

- Peteet, J. (2000): "Male gender and rituals of resistance in the Palestinian Intifada: A cultural politics of violence". In: M. Ghoussoub \& E. Sinclai-

Webb (red.), Imagined masculinities: Male identity and culture in the modern Middle East. Saqi, London.

- Pleck, J. H., \& Sawyer, J. (red.) (1974): Men and masculinity. Prentice Hall, Englewood Cliffs, New Jersey

- Ratnesar, R., \& Zabriskis, P. (26. januar 2004):

"The rise of the Jibadists". Time, pp. 30-31.

- Sachs, S. (22. juli 2000): "In Iran, more women leaving the nest for university". New York Times.

Hentet fra www.library.cornell.edu/colldev/mideast/irnwmnz.htm

• Saghieh, H. (2000): ““That's how I am, world!”: Saddam, manhood and monolithic image". In: M. Ghoussoub \& E. Sinclai-Webb (red.), Imagined masculinities: Male identity and culture in the modern Middle East. Saqi, London.

- Said, E. (4. august 2003): “Orientalism 25 years later”. CounterPunch. Hentet 10. februar 2004 fra www.counterpunch.org/said08052003.html. - Salehi Esfahani, H., \& Taheripour, F. (2002):
"Hidden public expenditures and the economy in Iran". International Journal of Middle East Studies, 34, 691-718.

. Schacht, S. P., \& Ewing, D. W. (red.) (1998): Feminism and men: Reconstructing gender relations. New York University Press, New York.

- Shehadeh, L. R. (2003): The idea of women in fundamentalist Islam. University Press of Florida, Gainesville.

- Sinclair-Webb, E. (2000): “"Our bulent is now a commando": Military service and manhood in Turkey". In: M. Ghoussoub \& E. Sinclai-Webb (red.), Imagined masculinities: Male identity and culture in the modern Middle East. Saqi, London. - Soroush, A. (2000): Reason, freedom and democracy in Islam (M. Sadri \& A. Sadri, red. og oversættelse), Oxford University Press, Oxford, UK. - UNESCO Institute of Statistics (2000-2001): Statistical tables. Hentet fra www.uis.unesco.org/TEMPLATE/html/Exceltables/education/ger_tertiary.xls.

. FN's befolkningsorganisation (UNPD) (2002): Annex tables. Hentet fra www.un.org/esa/population/publications/wpp2002/wpp2002annextables.PDF.

- Wickham, C. (2002): Mobilizing Islam: Religion, activism and political change in Egypt. Columbia University Press, New York.

- Wiktorowicz, Q. (2001): The management of Islamic activism: Salafis, the Muslim brotherhood and state power in Jordan. State University of New

York Press, Albany.

\section{SUMMARY}

A core component of the ideology of the Islamic Revolution was reformulation of gender discourse around an Islamic hypermasculinity that produced/ promoted three ideals of manhood: Mullahs who are the interpreters of the quran and shariat; martyrs, the young men who abide the dictates of the mullabs and sacrifice themselves for the republic; and ordinary men, who are perceived to have benefited from this hypermasculinity. It is argued that economic hardship and socio-political pressure assail all men. Also, they pay for gender discrimination against women in general and women of their own social group in particular.

Shahin Gerami, Professor of Sociology and Gender Studies, South West Missouri State University. 